\title{
Self-Care Practices of Primipara Women Regarding Breast Engorgement
}

\author{
Eman Abd El-hady Shehata Abd El-hady ${ }^{1}$, Alya Mohamed El-Refaey ${ }^{2}$ \\ Manal Abd-alla Sayed Ahmed Gaheen ${ }^{3}$. \\ ${ }^{I}$ Demonstrator of Maternity and Gynecological Nursing Department, Faculty of Nursing, Tanta \\ University, Egypt \\ ${ }^{2}$ Lecturer of Maternity and Gynecological Nursing Department, Faculty of Nursing, Tanta University, \\ Egypt \\ ${ }^{3}$ Assist. Prof of Maternity and Gynecological Nursing Department, Faculty of Nursing, Tanta \\ University, Egypt.
}

\begin{abstract}
Breast engorgement is a painful condition affects postnatal women, and lead to unsuccessful breastfeeding. So, there is urgent need to increase women's knowledge and to improve their self-care practices regarding breast engorgement. Aim: The present study aimed to assess self-care practices of primipara women regarding breast engorgement. Subjects and method: The study was conducted at postpartum departments, outpatient clinics and Neonatal intensive care units affiliated to Tanta University Hospital, El-Menshawy General Hospital and El-Mabara Hospital, in addition to Maternal and Child Health Centers at Botros and Sager. Convenience sample of 200 women were included in the study. Four tools were used for the collection of data: Tool I: Structured interview schedule, consisted of two parts: Part (1): Socio-demographic data of the women. Part (2): Reproductive history. Tool II: Knowledge of primipara women regarding breast engorgement. Tool III: Self-care practices of primipara women regarding breast engorgement. Tool IV: LATCH Breastfeeding Charting Scale. Results: The study revealed that almost three quarters (77.5\%) of women had poor level of knowledge followed by $(17.0 \%$ and $5.5 \%$ respectively) of them had fair and good level of knowledge. The entire of the studied women with breast engorgement had unsatisfactory practices. It also illustrated that, only $27.0 \%$ had well breastfeeding. Conclusion: There was poor knowledge, as well as unsatisfactory level of self -care practices regarding breast engorgement among primipara post-natal women. Recommendations: the study recommended developing antenatal classes for all women to increase their knowledge and enhance their self-care practices regarding breast engorgement.
\end{abstract}

Keywords: Self-Care Practices, Primipara, Breast Engorgement. 


\section{Introduction}

Puerperium is the period following childbirth during which the woman's body in general and the genital organs in particular return to the pre-pregnant state. During puerperium the women experience many physiological and psychological changes and problems. The most significant problem observed at this time is breast engorgement (BE) especially among primipara women ${ }^{(1,2)}$. The breast is an accessory organ of female reproductive system, which is concerned with lactation (3). Breast engorgement and nipple trauma are the most common problems associated with breast feeding and considered as a most significant factors that interfere with breast feeding during the first weeks of motherhood $^{(4)}$.

Breast engorgement can be defined as painful sensation due to expansion and pressure exerted by the synthesis and storage of breast milk usually during the third day after childbirth (5). The prevalence of breast problems during the postpartum period is very high. It is evidenced that the incidence rate of breast engorgement throughout the world in 2019 was $65 \%-75 \%$ among lactating women but in Egypt it was $82 \%(6,7)$.

There are many common causes of breast engorgement, some are related to the women such as inverted and flat nipple, inappropriate feeding technique, imbalance of hormones production and increase breast vascularity. Others are related to infant such as prematurity, congenital anomalies as cleft lip and palate, poor attachment and ineffective suckling ${ }^{(7)}$.

The common signs and symptoms of breast engorgement are enlarged, heavy, swollen and painful breast, the nipple may be stretched flat, low grade fever; less than $39^{\circ} \mathrm{c}$ and shiny breast ${ }^{(8)}$. Nurses who work at obstetrical departments have a great role in to providing health education for women during antenatal and post-natal period regarding the importance of breast feeding for both women and infants, proper breast feeding technique and the most common problems which can occur during lactation $^{(9)}$.

Breast engorgement has a serious effect on milk production as it causes milk stasis inside the breast, increases pressure in the milk ducts, which decrease the flow of blood and milk production. Increased milk pressure can cause some alveolar cells and myoepithelial cells to shrink and die off. This atrophy of milk producing cells can permanently compromise the milk producing ability of the breast which results in permanent harming for breast tissue. So the risk for infection will 
increase because bacteria are not being removed by the lymphatic system at the normal rate. It also has adverse effect on the letdown mechanism; as a result of poor latch which cause severe breast problems such as sore nipples, mastitis, breast abscess and plugged milk ducts ${ }^{(10,11)}$. Although the breast engorgement cause severe consequence for the mother and her infant, the studies have shown that women's awareness regarding breast engorgement is low especially among primipara women. So, it is very important to assess self-care practices of primipara women regarding breast engorgement.

\section{Aim of the Study}

The aim of this study was to assess selfcare practices of primipara women regarding breast engorgement.

\section{Research question:}

What are the self-care practices of primipara women regarding breast engorgement?

\section{Subjects and Method}

\section{Study Design:}

Descriptive research design was used in this study.

\section{Setting:}

This study was conducted in the following settings:
- Postpartum departments, outpatient clinics and neonatal intensive care units at Tanta University Hospital, ElMenshawy General Hospital and ElMabara Hospital affiliated to Ministry of Health and population.

- Maternal Child Health Centers at Botros and Siger affiliated to the Ministry of Health and population.

\section{Subjects:}

- Total convenient sample of 200 women were selected from the previously mentioned settings within 6 months.

- The subjects of this study were selected according to the following inclusion criteria:

- Women at post-natal period.

- Age range from 20-35 years old.

- Breastfeed their infants within the first 6 weeks after delivery.

- Free from breast infection.

- Willing to participate in the study.

- No neonate congenital malformation interferes with breast feeding (cleft lip and cleft palate).

\section{Tools of data collection:}

Four tools were designed based on the recent related literatures ${ }^{(2,8,10-12)}$ to collect the required data regarding the study elements. 


\section{Tool I: Structured interview schedule:}

This tool was developed by the researcher to collect basic data. It included two parts as follows:

Part (1): Socio-demographic data of the women:

This part assessed the socio-demographic data of the women such as age, educational level, occupation, residence, marital status, age at marriage, duration of the current marriage, type of family, number of family members and family income.

\section{Part (2): Reproductive history:}

This part included two parts:

\section{A. Obstetric history: It included} gravidity number, gestational age, time of initial antenatal visit, number and place of antenatal follow up visits, attendance, number, and place of antenatal care classes, topics of health education, the mode of delivery, type of anesthesia if used, length of labor, presence of episiotomy, any problem during labor and previous history of breast engorgement.

B. Clinical data of women: It included number of postpartum days, breast feeding initiation time, duration and frequency of breast feeding, maternal position during breast feeding and uses of both breasts for infant feeding.
Tool II: Knowledge of primipara women about breast engorgement.

This tool was developed and used by the researcher to assess knowledge of primipara women about breast engorgement. It included 7 items (definition, risk factors, signs and symptoms, complications, women's practices to relief breast engorgement, source of knowledge and the role of nurse to relief breast engorgement).

The scoring system regarding women's knowledge about breast engorgement was as follow:

- Incorrect answer or didn't know was given a score of $(0)$.

- Correct and incomplete answer was given a score of (1).

- Correct and complete answer was given a score of (2).

The total knowledge score level was calculated by ( 7 questions $x 2=14$ point). This was categorized as follows:

- Poor level of knowledge < 60\%. $=(0-8$ scores $)$

- Fair level of knowledge $60 \%<75 \%$. = (9-10 scores)

- Good level of knowledge $\geq 75 \%$. = (11-14 scores) 
Tool III: Self-care practices of primipara women regarding breast engorgement:

This tool was developed and used by the researcher to assess self-care practices that should be done by primipara women regarding breast engorgement. It included the following:

- Use of moist heat on breasts for few minutes before breast feeding.

- Take a brief hot shower before breast feeding.

- Use cold compresses for 10 minutes after feeding.

- Gently massage and compress the breast when the neonate pauses between sucking.

- Wear well fitted supportive brassiere.

- Breast massage or relaxation technique.

- Use of breast pump.

- Apply cold cabbage leaves on the breasts.

- Nurse on neonate's cues “on demand".

- Express breast milk manually before putting the neonate to the breast.

- Increase frequency of breast feeding.

- Feed the neonate at least 15 to 20 minutes at each breast or until the breast becomes soft.

- Ensure correct latch and positioning of the neonate during breast feeding.
- Use gel packs on the breast.

- Use scraping technique (Gua Sha therapy).

- Take analgesic drug to reduce pain.

- Apply lavender or fennel oil to the breast to enhance milk flow and prevent or alleviate risks of mastitis or clogged ducts.

Scoring system of women's self-care practices regarding relieve of breast engorgement was as the following:

- Responses were ranged from (1:2) where 1 referred to not done and 2 referred to done.

The total score of women practices was calculated as follows:

- $\quad$ Unsatisfactory practice $<60 \%$. $(\leq 27)$

- $\quad$ Satisfactory practice $\geq 60 \%$. $\quad(28 \leq$ 34)

\section{Tool IV: LATCH Breastfeeding} Charting Scale:

This tool was adopted from Jensen D., Wallace S., and Kelsay $P$ (1994) ${ }^{(12)}$ to assess effectiveness of breast feeding. The system assigned a numerical score (0.1.2) to five key breast feeding component identified by the letters of the acronym LATCH:"L" for how well the infant latches onto the breast, "A" for the amount of audible swallowing noted, " $\mathrm{T}$ " for the women nipple type / condition, "C" for the women level of comfort and " $\mathrm{H}$ " for the 
amount of help the woman needs to hold her infant to the breast. The total score ranged from 0 to 10 , with the higher score represented successful breastfeeding.

The total scoring system ranked as follows:

- Poor breast feeding

- Fair breast feeding

- Well breast feeding

\section{Method}

\section{Administrative design:}

Written approvals: official letter clarifying the purpose of the study was obtained from the Faculty of Nursing and submitted to the responsible authorities of the selected settings to obtain their approval and cooperation for carrying out the study.

\section{Ethical considerations:}

Informed consent was obtained from women who accepted to participate in the study after explaining the purpose of the study, confidentiality of information was maintained, benefits and right of women to withdraw from the study at any time if desired. The nature of the study did not cause any harm and/or pain for the subjects.

\section{Developing the tools:}

- Tools (I, II, and III)) were developed by the researcher after reviewing recent related literature ${ }^{(2,8,10,11)}$.
- Tool IV was adopted from Jensen D., Wallace S., and Kelsay P (1994) ${ }^{(12)}$.

- The study tools were translated into Arabic language and then tested for face and content validity by jury of five professors expertise in the field of Obstetrics and Gynecological nursing before conducting the study.

- The study tools were tested for its reliability by using Cronbach's Alpha test. The reliability of tool II which assessed knowledge of primipara women about breast engorgement was 0.948 , the reliability of tool III which assessed selfcare practices done by primipara women regarding breast engorgement was 0.806 and the reliability of tool IV which assessed effectiveness of breast feeding was 0.801 indicating high reliability of the study tools.

\section{Pilot study}

After development of the tools, a pilot study was carried out on $10 \%$ of the sample "20" primpara postnatal women from the previously mentioned settings. This pilot study was conducted before the actual data collection.

\section{The purposes of the pilot study were to:}

- Ascertain the feasibility and applicability of the developed tools. 
- Detect any problem peculiar to clarity of the statements that might interfere with the process of data collection.

\section{Results of the pilot study:}

- The pilot study revealed that the sentences of the tools were clear and relevant. Few words and statements were rephrased and /or modified. Then, the tools was reconstructed and made ready for use. Data obtained from the pilot study were excluded from the actual study sample.

\section{Actual study (field work)}

- Data were collected at the morning shifts in Postpartum departments and outpatient clinics of the previously mentioned hospitals and from Maternal and Child Health Centers from 9:00 a.m. to 1.00 p.m. But data were collected from 1.00 p.m. to 3.00 p.m. in neonatal intensive care units at the time of maternal visiting. The process of data collection began from January 2020 until the end of June 2020, three times per week until the predetermined sample size were collected.

- The structured interview schedule was applied individually for each woman at the postpartum outpatient clinics, maternal and child health centers $(\mathrm{MCH})$, postpartum departments, and the neonatal intensive care units.
- All subjects who had the inclusion criteria at the time of data collection were included in the study. Data were collected within 15-20 minute. Firstly, the researcher introduced herself to each woman and explained the aim of the study. Then, the researcher measured the women's body temperature and examined their breast to exclude the cases of breast infection.

- Data were collected by the researcher using the previously mentioned tools, Tool I: used to collect data about sociodemographic characteristic and reproductive history of the women, Tool II: used to assess knowledge of primipara women about breast engorgement, Tool III: used to assess self-care practices of primipara women regarding breast engorgement, Tool IV: LATCH Breastfeeding Charting Scale was used to assess the effectiveness of breast feeding.

- Instructional booklet was prepared by the researcher and given to women to help increase their knowledge and promote their practices regarding breast engorgement.

\section{Limitation of the study:-}

\section{This study had some limitations}

- From January to March the researcher collected data from all previously 
mentioned setting, while from April the researcher found difficulties in collecting data from outpatient clinics, maternal and child health centers and neonatal intensive care units due to coronavirus; Therefore the researcher collected the remaining data from postpartum departments only.

\section{Statistical analysis:}

- The collected data were organized, tabulated and statistically analyzed using SPSS software (Statistical Package for the Social Sciences, version 19, SPSS Inc. Chicago, IL, USA).

- For quantitative data, the range, mean and standard deviation were calculated. For qualitative categorical set of data frequency, percentage or proportion of each category, comparison between two groups and more was done using Chi-square $\operatorname{test}(\chi 2)$.

- For comparison between means of two groups of non-parametric data of independent sample, $\mathrm{Z}$ value of Mannwhitney test was used. For comparison between more than two means of nonparametric data, Kruskal-Wallis $(\chi 2$ value) was calculated. Correlation between variables was evaluated using Pearson's correlation coefficient (r).
Significance was adopted at $\mathrm{p}<0.05$ for interpretation of results of the tests $^{(13)}$.

\section{Results:}

Table (1): Shows the distribution of the studied primipara post-natal women according to their socio-demographic characteristics. It is noticed that slightly more than four fifth of women $(81.5 \%)$ were 20 to less than 30 years old with mean age 25.19 years $\mathbf{\pm 4 . 1 8}$. The table also reveals that slightly less than three fifth of the women (56.0\%) were from rural areas. Also it is found that nearly three quarter of women $(72.5 \%)$ were married at age of 18 to less 25 with mean age at marriage of $\mathbf{2 2 . 9 4}$ years $\mathbf{\pm 4 . 0 8}$. The mean duration of current marriage was 1.94 years $\mathbf{\pm 1 . 0 9}$. Regarding the educational level, $37.0 \%$ of the women had secondary school and only $8.0 \%$ were illiterate. Concerning occupation, the vast majority of them were housewife $(90.0 \%)$. The table also illustrates that nearly three fifth of women $(58.0 \%)$ were from nuclear families and had three family members, and slightly more than four fifth $(82.0 \%)$ had enough family income.

Table (2): Shows the distribution of the studied primipara post-natal women according to their Obstetric history. The majority of women $(86.0 \%$ and $84.0 \%$ 
respectively) were primigravida and attended for antenatal care regularly. Concerning the time of initial antenatal visit, the vast majority of the women (98.0\%) had initial antenatal visit at the first trimester. As regard the number and place of antenatal follow up visits, the majority of the women $(84.0 \%$ and $83.0 \%$ respectively) had four or more times antenatal visits and had antenatal care at the private hospitals or clinics.

Concerning antenatal care classes; the majority of the women $(88.0 \%)$ didn't attend antenatal care classes. As regarding to the number of antenatal care classes' attended, $62.5 \%$ attended one to two times and received the educational classes by doctors and $66.7 \%$ attended antenatal care classes at health centers and $\mathrm{MCH}$ centers. Breast feeding education was the most common topic of health education classes that was mentioned by $83.3 \%$ of women. As regard to the mode of delivery, almost three quarters $(77.0 \%)$ had cesarean section and $23.0 \%$ had normal vaginal delivery; $91.3 \%$ of normal vaginal delivery had episiotomy. The vast majority of the women (97.4\%) had spinal anesthesia during cesarean section. The mean length of normal vaginal delivery was $\mathbf{1 3 . 3 7}$ hours $\pm \mathbf{5 . 8 9}$, but the mean length of cesarean section labor was $\mathbf{1 . 3 7}$ hours \pm 0.53

Regarding the presence of complications during labor, the vast majority of the women (97.0\%) hadn't complication during labor and only $3.0 \%$ of women had complications such as a result of normal vaginal delivery and half of them had intrapartum hemorrhage.

Table (3): Shows the distribution of the studied primipara post-natal women according to their reproductive clinical data. The mean number of postpartum days is $5.84 \pm$ 8.57. Concerning the breast feeding initiation time, nearly half of women $(49.0 \%)$ initiated breast feeding within two hours after delivery. Regarding the duration of breast feeding, the vast majority of women $(98.0 \%)$ reported that the duration of breast feeding was 10 minutes. As regard the frequency of breast feeding, slightly more than four fifth of the women $(81.5 \%)$ fed their infants on demand. All women used sitting position while feeding their infants and only $3.5 \%$ used both sitting and lying positions. The vast majority of them $(96.0 \%)$ fed their infants from both breasts.

Figure (1): Shows the distribution of the studied primpara post-natal women according to their total score level of 
knowledge regarding breast engorgement. More than three quarters of women $(77.5 \%)$ had poor level of knowledge followed by $17.0 \%$ of them had fair level of knowledge and only $5.5 \%$ of them revealed good level of knowledge with range 3-13 and Mean \pm SD $6.76 \pm 2.38$.

Figure (2): Shows the distribution of the studied primpara post-natal women according to their source of knowledge. The table reveals that nearly half $(46.5 \%)$ of women mentioned that their family was the primary source of knowledge regarding breast engorgement, while $31.9 \%$ of them stated that friends, as well as doctor or nurse, media, books and magazine were other sources of their knowledge (reported by $19.3 \%, 5.7 \%$ and $2.3 \%$ respectively).

Table (4): Shows the distribution of the studied primpara post-natal women according to their self-care practices regarding breast engorgement. The majority of the women (85\%) didn't suffer from breast engorgement during post-natal period and only $15 \%$ of them actually suffered from breast engorgement during post-natal period. Regarding their practices that were performed to relief breast engorgement, all women (100\%) mention that they express their breasts manually before putting the infant to the breast, $96.7 \%$ increased the frequency of breastfeeding, 93.3\% used breast pump, $90.0 \%$ nursed their infants on demand, used correct latch and positioning of infant during breastfeeding and fed their infants at least 15 to 20 minutes from each breast or until breast become soft. On the other hand, $(23.3 \%, \quad 20.0 \%$ and $20.0 \%$ respectively) of them used moist heat on breast for few minutes before breastfeeding, made gently massage, compressed the breast when the infant pauses between sucking, and took analgesic to reduce pain.

In relation to the anticipated practices that should be done by women who didn't experience breast engorgement, about $70.0 \%$ didn't know specific measures, $33.5 \%$ increased frequency of breastfeeding, and $32.3 \%$ squeezed the breast by hands. The table also shows that $(2.4 \%, 1.2 \%, 1.2 \%$ and $1.2 \%$ respectively) of them reported using hot compression, breast massage by hand, frequent breast suction and using sedation.

Figure (3): Shows the distribution of the studied primipara post-natal women according to total level of LATCH Breastfeeding Charting Scale. It was illustrated that, $63.5 \%$ of women were fair breastfeeding, $27.0 \%$ were well breastfeeding and only 9.5 were poor breastfeeding.

Table (5): Shows the relationship between studied primipara post-natal women's socio-demographic data and their total 
knowledge scores about breast engorgement. The table revealed that there are significant relationship between women's occupation, family income and their total knowledge scores $\left(\mathrm{P}=0.027^{*}\right.$ and $0.039^{*}$ respectively). On the other hand, there was no significant relationship between women's age, residence, age at marriage, educational level, type of family, number of family members and their total knowledge scores $(\mathrm{P}=0.654,0.254,0.313$, $0.371,0.430$ and 0.613 respectively).

Table (6): Shows the relationship between studied primipara post-natal women's with breast engorgement socio-demographic data and their total self-care practice scores regarding breast engorgement. The table revealed that there were significant relationships between total self-practice scores about breast engorgement and both women's educational level and occupation $(\mathrm{P}=(0.007 *$ and $0.001 *$ respectively). On the other hand, there was no significant relationship between women's age, residence, age at marriage, type of family, number of family members and their total self-care practice scores about breast engorgement $(\mathrm{P}=0.249,0.153,0.516$, 0.291 and 0.077 respectively).

Table (7) shows the relationship between studied primipara post-natal women's socio-demographic data and their total Latch Breastfeeding Scale Scores. The table illustrated that there were significant relationships between total Latch Breastfeeding Scale scores and the following; women's age $\left(\mathrm{P}=0.017^{*}\right)$, educational level $(\mathrm{P}=0.0001 *)$ occupation $\left(\mathrm{P}=0.016^{*}\right)$, type of family $\left(\mathrm{P}=0.039^{*}\right)$ and number of family members $\left(\mathrm{P}=0.0001^{*}\right)$. On the other hand, there was no significant relationship between women's residence, age at marriage, family income and their total Latch Breastfeeding Scale scores $(\mathrm{P}=0.527,0.965$ and 0.503 respectively). 
Table (1): Distribution of the studied primipara post-natal women according to their socio-demographic characteristics $(n=200)$.

\begin{tabular}{|c|c|c|}
\hline \multirow[t]{2}{*}{ Variables } & \multicolumn{2}{|c|}{$\begin{array}{l}\text { The studied post-natal women } \\
(\mathbf{n = 2 0 0 )}\end{array}$} \\
\hline & $\mathbf{N}$ & $\%$ \\
\hline \multicolumn{3}{|l|}{ •Age: (years) } \\
\hline $20-<30$ & 163 & 81.5 \\
\hline $30-35$ & 37 & 18.5 \\
\hline $\begin{array}{l}\text { Range } \\
\text { Mean } \pm \text { SD }\end{array}$ & \multicolumn{2}{|c|}{$\begin{array}{c}20-35 \\
25.19 \pm 4.18\end{array}$} \\
\hline \multicolumn{3}{|l|}{ •Residence: } \\
\hline Urban & 88 & 44.0 \\
\hline Rural & 112 & 56.0 \\
\hline \multicolumn{3}{|l|}{-Age at marriage: } \\
\hline $18-<25$ & 145 & 72.5 \\
\hline $25-32$ & 55 & 27.5 \\
\hline $\begin{array}{l}\text { Range } \\
\text { Mean } \pm \text { SD }\end{array}$ & \multicolumn{2}{|c|}{$\begin{array}{c}18-32 \\
22.94 \pm 4.08\end{array}$} \\
\hline $\begin{array}{l}\text {-Duration of current marriage: (years) } \\
\text { Range } \\
\text { Mean } \pm \text { SD }\end{array}$ & \multicolumn{2}{|c|}{$\begin{array}{l}0.83-5.00 \\
1.94 \pm 1.09\end{array}$} \\
\hline \multicolumn{3}{|l|}{ •Educational level: } \\
\hline Illiterate & 16 & 8.0 \\
\hline Read and write & 42 & 21.0 \\
\hline Primary school & 41 & 20.5 \\
\hline Secondary school & 74 & 37.0 \\
\hline College & 27 & 13.5 \\
\hline \multicolumn{3}{|l|}{-Occupation: } \\
\hline House wife & 180 & 90.0 \\
\hline Worked & 20 & 10.0 \\
\hline \multicolumn{3}{|l|}{-Type of family: } \\
\hline Nuclear family & 116 & 58.0 \\
\hline Extended family & 84 & 42.0 \\
\hline \multicolumn{3}{|l|}{-Number of family members: } \\
\hline 3 & 116 & 58.0 \\
\hline 4 & 56 & 28.0 \\
\hline 5 & 16 & 8.0 \\
\hline 6 and 8 & 12 & 6.0 \\
\hline \multicolumn{3}{|l|}{-Family income from women view: } \\
\hline Enough & 164 & 82.0 \\
\hline Not enough & 36 & 18.0 \\
\hline
\end{tabular}


Table (2): Distribution of the studied primipara post-natal women according to their Obstetric history $(n=200)$.

\begin{tabular}{|c|c|c|}
\hline \multirow[t]{2}{*}{ Obstetric history data } & \multicolumn{2}{|c|}{$\begin{array}{l}\text { The studied post-natal women } \\
\qquad(\mathrm{n}=200)\end{array}$} \\
\hline & $\mathbf{N}$ & $\%$ \\
\hline \multicolumn{3}{|l|}{-Gravidity number: } \\
\hline Primigravida & 172 & 86.0 \\
\hline Multigravida & 28 & 14.0 \\
\hline \multicolumn{3}{|l|}{ - Gestational age (weeks): } \\
\hline $\begin{array}{l}\text { Range } \\
\text { Mean } \pm \text { SD }\end{array}$ & \multicolumn{2}{|c|}{$\begin{array}{c}36-42 \\
39.32 \pm 1.30\end{array}$} \\
\hline \multicolumn{3}{|l|}{ •Follow up during pregnancy: } \\
\hline Regularly & 168 & 84.0 \\
\hline If necessary & 32 & 16.0 \\
\hline \multicolumn{3}{|l|}{-Time of initial antenatal visit: } \\
\hline At the first three months of pregnancy & 196 & 98.0 \\
\hline At the second three months of pregnancy & 4 & 2.0 \\
\hline \multicolumn{3}{|l|}{-Number of antenatal visits: } \\
\hline$<4$ times & 32 & 16.0 \\
\hline$\geq 4$ times & 168 & 84.0 \\
\hline \multicolumn{3}{|l|}{-Place of antenatal follow up visits:\# } \\
\hline Governmental Hospitals & 12 & 6.0 \\
\hline Private hospitals or clinics & 166 & 83.0 \\
\hline Health Center / MCH Centers & 29 & 14.5 \\
\hline \multicolumn{3}{|l|}{ •Attendance of antenatal care classes: } \\
\hline Yes & 24 & 12.0 \\
\hline No & 176 & 88.0 \\
\hline If yes, number of antenatal care classes: & \multicolumn{2}{|c|}{$(n=24)$} \\
\hline 1-2 times & 15 & 62.5 \\
\hline 3-4 times & 5 & 20.8 \\
\hline$>4$ times & 4 & 16.7 \\
\hline If yes, who gave antenatal care classes: & \multicolumn{2}{|c|}{$(n=24)$} \\
\hline Nurses & 9 & 37.5 \\
\hline Doctors & 15 & 62.5 \\
\hline
\end{tabular}




\begin{tabular}{|c|c|c|}
\hline ${ }^{\text {Place of antenatal care classes: }}$ & \multicolumn{2}{|c|}{$(n=24)$} \\
\hline Private hospitals or clinics & 8 & 33.3 \\
\hline Health centers/ MCH Centers & 16 & 66.7 \\
\hline -Topics of health education classes: \# & \multicolumn{2}{|c|}{$(n=24)$} \\
\hline Nutrition during pregnancy & 12 & 50.0 \\
\hline Regular follow-up during pregnancy & 5 & 20.8 \\
\hline Vaccination during pregnancy & 1 & 4.2 \\
\hline Rest and Sleep during pregnancy & 7 & 29.2 \\
\hline Breastfeeding education & 20 & 83.3 \\
\hline \multicolumn{3}{|l|}{-Mode of delivery: } \\
\hline Normal vaginal delivery & 46 & 23.0 \\
\hline Cesarean section (CS) & 154 & $\mathbf{7 7 . 0}$ \\
\hline If CS, Type of anesthesia used: & \multicolumn{2}{|c|}{$(\mathbf{n}=154)$} \\
\hline Spinal anesthesia & 150 & 97.4 \\
\hline General anesthesia & 4 & 2.6 \\
\hline \multicolumn{3}{|l|}{-Length of labor (Hours): } \\
\hline \multicolumn{3}{|l|}{-Normal vaginal delivery: } \\
\hline $\begin{array}{l}\text { Range } \\
\text { Mean } \pm \text { SD }\end{array}$ & \multicolumn{2}{|c|}{$\begin{array}{l}9.00-25.00 \\
13.37 \pm 5.89\end{array}$} \\
\hline \multicolumn{3}{|l|}{-Cesarean section (C.S) (Hours): } \\
\hline $\begin{array}{l}\text { Range } \\
\text { Mean } \pm \text { SD }\end{array}$ & \multicolumn{2}{|c|}{$\begin{array}{l}1.00-3.00 \\
1.37 \pm 0.53\end{array}$} \\
\hline $\begin{array}{l}\text { - If normal vaginal delivery, "episiotomy was } \\
\text { performed": }\end{array}$ & \multicolumn{2}{|c|}{$(n=46)$} \\
\hline Yes & 42 & 91.3 \\
\hline No & 4 & 8.7 \\
\hline \multicolumn{3}{|l|}{-Complications during labor: } \\
\hline Yes ( of normal labor) & 6 & 3.0 \\
\hline No & 194 & 97.0 \\
\hline If yes, what are these complications? & \multicolumn{2}{|c|}{$(n=6)$} \\
\hline Intrapartum hemorrhage. & 3 & $\mathbf{5 0 . 0}$ \\
\hline Fetal distress & 2 & 33.3 \\
\hline Umbilical cord prolapse & $\mathbf{1}$ & 16.7 \\
\hline
\end{tabular}


Table (3) Distribution of the studied primipara post-natal women according to their reproductive clinical data $(n=200)$.

\begin{tabular}{|c|c|c|}
\hline \multirow[t]{2}{*}{ Reproductive clinical data } & \multicolumn{2}{|c|}{$\begin{array}{l}\text { The studied post-natal women } \\
(\mathbf{n = 2 0 0 )}\end{array}$} \\
\hline & $\mathbf{N}$ & $\%$ \\
\hline \multicolumn{3}{|l|}{-Number of postpartum days: } \\
\hline $\begin{array}{l}\text { Range } \\
\text { Mean } \pm \text { SD }\end{array}$ & \multicolumn{2}{|c|}{$\begin{array}{l}0.5-32.00 \\
5.84 \pm 8.57\end{array}$} \\
\hline \multicolumn{3}{|l|}{-Breast feeding initiation time: } \\
\hline Immediately after delivery & 21 & $\mathbf{1 0 . 5}$ \\
\hline Two hours after delivery & 98 & 49.0 \\
\hline More than two hours & 81 & 40.5 \\
\hline \multicolumn{3}{|l|}{-Duration of breast feeding: } \\
\hline 10 minutes & 196 & 98.0 \\
\hline 20 Minutes & 4 & 2.0 \\
\hline \multicolumn{3}{|l|}{-Frequency of breast feeding: } \\
\hline As infant demand & 163 & 81.5 \\
\hline Every two hours & 16 & 8.0 \\
\hline Every three hours or more & 21 & 10.5 \\
\hline \multicolumn{3}{|c|}{-Maternal position during breast feeding: \# } \\
\hline Sitting position & 200 & 100 \\
\hline Side lying position & 7 & 3.5 \\
\hline \multicolumn{3}{|c|}{ - Feeding the infant from the both breasts: } \\
\hline Yes & 192 & 96.0 \\
\hline No & 8 & 4.0 \\
\hline If no, mention the causes: & \multicolumn{2}{|c|}{$(n=8)$} \\
\hline Inverted nipple & 7 & 87.5 \\
\hline Unable to feed from other side & $\mathbf{1}$ & $\mathbf{1 2 . 5}$ \\
\hline
\end{tabular}

\# More than one answer

Vol. 20 No. 1 February, 2021 


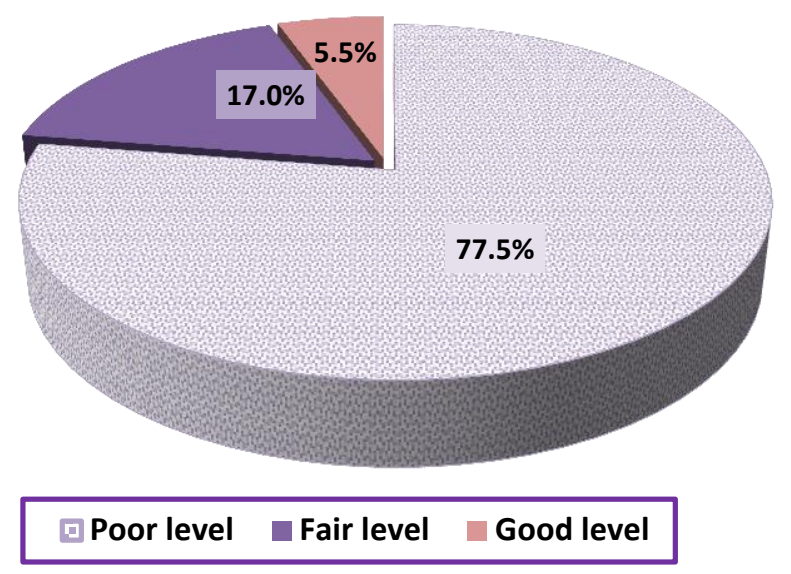

Figure (1): Distribution of the studied primpara post-natal women according to their total score level of knowledge regarding breast engorgement $(n=200)$.

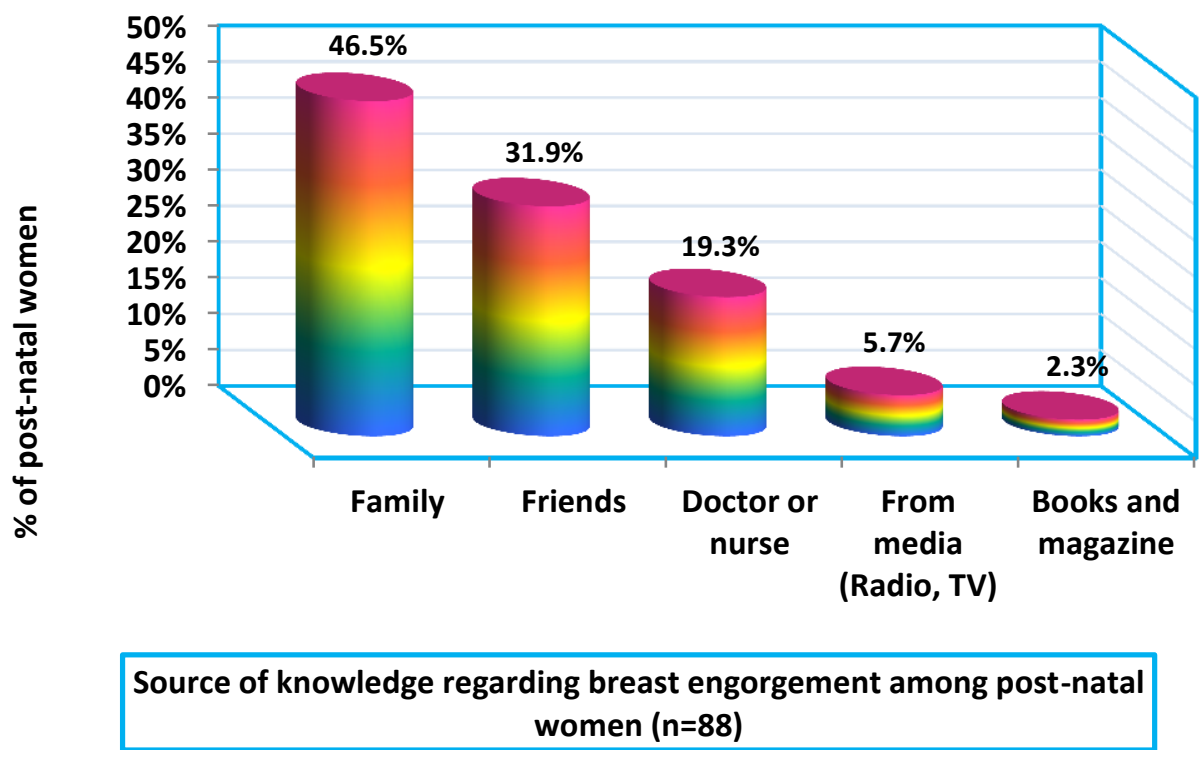

Figure (2): Distribution of the studied primpara post-natal women according to their source of knowledge regarding breast engorgement $(n=88)$. 
Table (4): Distribution of the studied primpara post-natal women according to their selfcare practices regarding breast engorgement $(n=200)$.

\begin{tabular}{|c|c|c|}
\hline \multirow[t]{2}{*}{$\begin{array}{l}\text { Self-care practices' items } \\
\text { (Each item was scores 1-2) }\end{array}$} & \multicolumn{2}{|c|}{$\begin{array}{c}\text { The studied post-natal } \\
\text { women } \\
(\mathbf{n}=200)\end{array}$} \\
\hline & $\mathbf{n}$ & $\%$ \\
\hline \multicolumn{3}{|l|}{-Occurrence of breast engorgement during post-natal period: } \\
\hline No & 170 & 85.0 \\
\hline Yes & 30 & $\mathbf{1 5 . 0}$ \\
\hline $\begin{array}{l}\text { If yes, what did the measures you did to relief breast } \\
\text { engorgement? \# }\end{array}$ & \multicolumn{2}{|c|}{$(\mathbf{n}=\mathbf{3 0})$} \\
\hline $\begin{array}{l}\text {-Use of moist heat on breast for few minutes before } \\
\text { breastfeeding }\end{array}$ & 7 & 23.3 \\
\hline $\begin{array}{l}\text {-Do gently massage and compress on the breast when the infant } \\
\text { pauses between sucking }\end{array}$ & 6 & 20.0 \\
\hline -Use breast pump & 28 & 93.3 \\
\hline -Nurse on infant's cues (on demand) & 27 & 90.0 \\
\hline -Correct latch and positioning of infant during breastfeeding & 27 & 90.0 \\
\hline -Express breast manually before putting the infant to the breast & 30 & 100 \\
\hline -Increase frequency of breastfeeding & 29 & 96.7 \\
\hline $\begin{array}{l}\text {-Feed the infant at least } 15 \text { to } 20 \text { minutes from each breast or } \\
\text { until breast become soft }\end{array}$ & 27 & 90.0 \\
\hline -Take analgesic to reduce pain & 6 & 20.0 \\
\hline \multicolumn{3}{|l|}{-Total self-practice scores: } \\
\hline $\begin{array}{l}\text { Range (18-36) } \\
\text { Mean } \pm \text { SD }\end{array}$ & \multicolumn{2}{|c|}{$\begin{array}{c}19-26 \\
23.23 \pm 1.79\end{array}$} \\
\hline \multicolumn{3}{|l|}{-Total self-practice level: } \\
\hline Unsatisfactory $(<60 \%)(18-28)$ & 30 & 100 \\
\hline Satisfactory $(60 \%-100 \%)(29-36)$ & $\mathbf{0}$ & $\mathbf{0}$ \\
\hline If no, what do you do if you have breast engorgement? \# & \multicolumn{2}{|c|}{$(n=170)$} \\
\hline -Don't know specific measures & 119 & $\mathbf{7 0 . 0}$ \\
\hline -Breast massage by hand & 2 & 1.2 \\
\hline -Sedation & 2 & 1.2 \\
\hline -Frequent squeezing of breast by hand & 55 & 32.3 \\
\hline -Hot compressions on the breast & 4 & 2.4 \\
\hline -Frequent breast suction & 2 & 1.2 \\
\hline -Frequent breastfeeding & 57 & $\mathbf{3 3 . 5}$ \\
\hline
\end{tabular}

\# More than one answer 


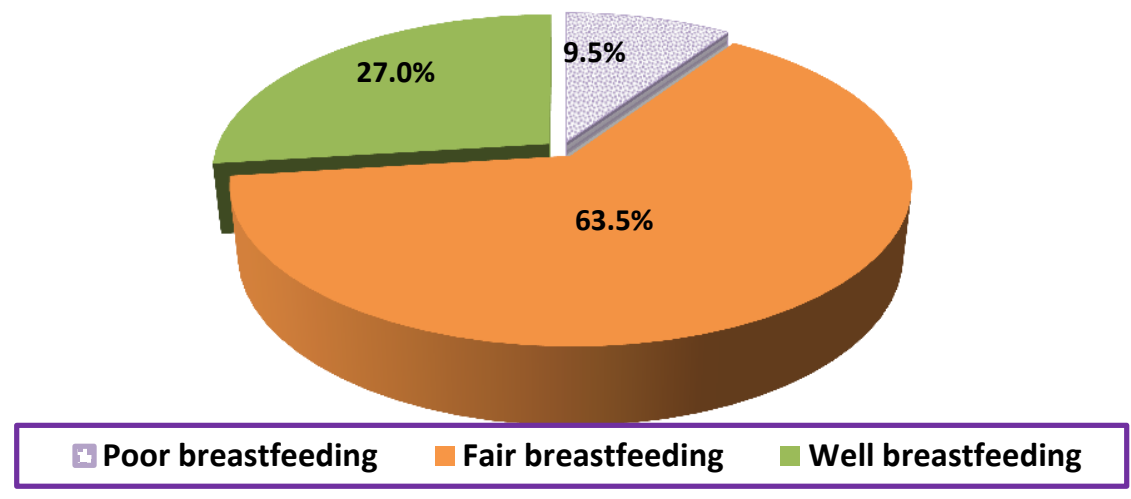

Figure (3): Distribution of the studied primipara post-natal women according to total Level of LATCH Breastfeeding Charting Scale ( $n=200)$. 
Table (5): Relationship between studied primipara post-natal women's sociodemographic data and their total knowledge scores $(n=200)$.

\begin{tabular}{|c|c|c|c|c|}
\hline \multirow{2}{*}{ Socio-demographic data } & \multicolumn{4}{|c|}{ Total knowledge scores among the studied post-natal women } \\
\hline & $\operatorname{Mean} \pm$ SD & $\chi^{2}$ value & $\mathrm{Z}$ value & $\mathbf{P}$ \\
\hline \multicolumn{5}{|l|}{ •Age: (years) } \\
\hline $20-<30$ & $6.72 \pm 2.34$ & & 0.449 & 0.654 \\
\hline $30-35$ & $6.92 \pm 2.60$ & & & \\
\hline \multicolumn{5}{|l|}{-Residence: } \\
\hline Urban & $6.98 \pm 2.52$ & & 1.145 & 0.254 \\
\hline Rural & $6.59 \pm 2.26$ & & & \\
\hline \multicolumn{5}{|l|}{-Age at marriage: } \\
\hline $18-<25$ & $6.65 \pm 2.32$ & & 1.011 & 0.313 \\
\hline 25-32 & $7.04 \pm 2.54$ & & & \\
\hline \multicolumn{5}{|l|}{ •Educational level: } \\
\hline Illiterate & $6.81 \pm 2.26$ & 4.265 & & 0.371 \\
\hline Read and write & $6.43 \pm 2.00$ & & & \\
\hline Primary school & $6.39 \pm 2.55$ & & & \\
\hline Secondary school & $6.77 \pm 2.16$ & & & \\
\hline College & $7.78 \pm 3.09$ & & & \\
\hline \multicolumn{5}{|l|}{-Occupation: } \\
\hline House wife & $6.59 \pm 2.26$ & & 2.216 & $0.027 *$ \\
\hline Worked & $8.30 \pm 2.90$ & & & \\
\hline \multicolumn{5}{|l|}{-Type of family: } \\
\hline Nuclear family & $6.65 \pm 2.38$ & & 0.791 & 0.430 \\
\hline Extended family & $6.92 \pm 2.38$ & & & \\
\hline \multicolumn{5}{|l|}{ •No. of family members: } \\
\hline 3 & $6.65 \pm 2.38$ & 2.676 & & 0.613 \\
\hline 4 & $7.09 \pm 2.19$ & & & \\
\hline 5 & $6.62 \pm 3.52$ & & & \\
\hline 6 & $7.00 \pm 2.45$ & & & \\
\hline 8 & $6.25 \pm 0.46$ & & & \\
\hline \multicolumn{5}{|l|}{$\begin{array}{l}\text {-Family income from women } \\
\text { view: }\end{array}$} \\
\hline Enough & $6.94 \pm 2.46$ & & 2.061 & $0.039 *$ \\
\hline Not enough & $5.92 \pm 1.79$ & & & \\
\hline
\end{tabular}


Table (6): Relationship between studied primipara post-natal women's with breast engorgement socio-demographic data and their total self-care practice scores regarding breast engorgement $(\mathbf{n}=\mathbf{3 0})$.

\begin{tabular}{|c|c|c|c|c|}
\hline \multirow[t]{2}{*}{ Socio-demographic data } & \multicolumn{4}{|c|}{$\begin{array}{l}\text { Total self-care practice scores of the studied post-natal women with breast } \\
\text { engorgement } \\
(n=30)\end{array}$} \\
\hline & Mean \pm SD & $\chi^{2}$ value & $Z$ value & $\mathbf{P}$ \\
\hline \multicolumn{5}{|l|}{ •Age: (years) } \\
\hline $20-<30$ & $23.04 \pm 1.60$ & & 1.178 & 0.249 \\
\hline $30-35$ & $24.00 \pm 2.45$ & & & \\
\hline \multicolumn{5}{|l|}{ •Residence: } \\
\hline Urban & $22.90 \pm 1.89$ & & 1.467 & 0.153 \\
\hline Rural & $23.90 \pm 2.02$ & & & \\
\hline \multicolumn{5}{|l|}{-Age at marriage: } \\
\hline $18-<25$ & $23.05 \pm 1.86$ & & 0.658 & 0.516 \\
\hline 25-32 & $23.50 \pm 1.73$ & & & \\
\hline \multicolumn{5}{|l|}{ •Educational level: } \\
\hline Read and write & $22.20 \pm 1.79$ & 12.226 & & $0.007 *$ \\
\hline Primary school & $22.00 \pm 2.00$ & & & \\
\hline Secondary school & $23.00 \pm 2.00$ & & & \\
\hline College & $24.87 \pm 3.84$ & & & \\
\hline \multicolumn{5}{|l|}{ •Occupation: } \\
\hline House wife & $22.65 \pm 1.46$ & & 3.468 & $0.001 *$ \\
\hline Worked & $25.14 \pm 1.46$ & & & \\
\hline \multicolumn{5}{|l|}{ •Type of family: } \\
\hline Nuclear family & $23.56 \pm 1.21$ & & 1.077 & 0.291 \\
\hline Extended family & $22.86 \pm 2.28$ & & & \\
\hline \multicolumn{5}{|l|}{ •No. of family members: } \\
\hline 3 & $23.56 \pm 1.21$ & 5.130 & & 0.077 \\
\hline 4 & $22.00 \pm 1.85$ & & & \\
\hline 5 & $24.00 \pm 2.45$ & & & \\
\hline \multicolumn{5}{|l|}{-Family income from women view: } \\
\hline Enough & $23.23 \pm 1.79$ & & - & - \\
\hline
\end{tabular}

NB. All women with breast engorgement $(n=30)$ had unsatisfactory practices $<60 \%$ of total scores)

$*$ Statistically significant $(\mathrm{P}<0.05) \cdot \chi^{2}$ value $=$ Kruskal Wallis test. 
Table (7): Relationship between studied primipara post-natal women's socio demographic data and total LATCH Breastfeeding Scale Scores $(n=200)$.

\begin{tabular}{|c|c|c|c|c|}
\hline \multirow[t]{2}{*}{ Socio-demographic data } & \multicolumn{4}{|c|}{$\begin{array}{c}\text { Total LATCH breastfeeding scale scores among the } \\
\text { studied post-natal women }(n=200)\end{array}$} \\
\hline & Mean \pm SD & $\begin{array}{l}\chi^{2} \text { value } \\
P\end{array}$ & $\begin{array}{c}Z \text { value } \\
P\end{array}$ & $\mathbf{P}$ \\
\hline \multicolumn{5}{|l|}{ •Age: (years) } \\
\hline $20-<30$ & $6.81 \pm 2.19$ & & 2.387 & $0.017^{*}$ \\
\hline $30-35$ & $5.67 \pm 1.49$ & & & \\
\hline \multicolumn{5}{|l|}{-Residence: } \\
\hline Urban & $6.51 \pm 2.36$ & & 0.527 & 0.527 \\
\hline Rural & $7.00 \pm 1.92$ & & & \\
\hline \multicolumn{5}{|l|}{-Age at marriage: } \\
\hline $18-<25$ & $6.65 \pm 2.18$ & & 0.043 & 0.965 \\
\hline $25-32$ & $6.45 \pm 1.97$ & & & \\
\hline \multicolumn{5}{|l|}{-Educational level: } \\
\hline Illiterate & $6.00 \pm 1.26$ & 25.120 & & $0.0001 *$ \\
\hline Read and write & $5.95 \pm 2.03$ & & & \\
\hline Primary school & $5.71 \pm 1.32$ & & & \\
\hline Secondary school & $7.11 \pm 2.30$ & & & \\
\hline College & $7.17 \pm 2.21$ & & & \\
\hline \multicolumn{5}{|l|}{-Occupation: } \\
\hline House wife & $5.60 \pm 1.39$ & & 2.407 & $0.016^{*}$ \\
\hline Worked & $6.71 \pm 2.16$ & & & \\
\hline \multicolumn{5}{|l|}{-Type of family: } \\
\hline Nuclear family & $6.33 \pm 2.20$ & & 2.068 & $0.039 *$ \\
\hline Extended family & $6.98 \pm 1.96$ & & & \\
\hline \multicolumn{5}{|l|}{-No. of family members: } \\
\hline 3 & $6.33 \pm 2.20$ & 9.873 & & $0.0001 *$ \\
\hline 4 & $7.82 \pm 1.72$ & & & \\
\hline 5 & $4.75 \pm 1.34$ & & & \\
\hline 6 & $6.00 \pm 0.00$ & & & \\
\hline 8 & $6.00 \pm 0.00$ & & & \\
\hline \multicolumn{5}{|l|}{$\begin{array}{l}\text {-Family income from women } \\
\text { view: }\end{array}$} \\
\hline Enough & $6.66 \pm 2.07$ & & 0.669 & 0.503 \\
\hline Not enough & $6.30 \pm 2.35$ & & & \\
\hline
\end{tabular}




\section{Discussion:}

Breastfeeding is important for women and their infants. This is based on the recommendation of major medical organizations; American Academy of Pediatrics (AAP), American Association of Family Physicians (AAFP) and Department of Health and Human Services (DHHS) who are recommended that infants should receive nothing rather than breast milk during the first 6 months of the infant's life, and continue receiving it for at least the first year (14). Breast engorgement can occur any time during lactation but it is most common within the first three to six days after delivery. Following proper breastfeeding technique is very important to prevent breast engorgement. The high incidence rate of breast engorgement is due to that women have poor knowledge regarding proper breastfeeding technique and breast engorgement. Previous studies recommended that, it is important to assess the knowledge level of the postnatal women regarding breast engorgement ${ }^{(15)}$. So, the present study aimed to assess selfcare practices of primipara women regarding breast engorgement.

Concerning socio-demographic characteristics of the studied primipara postnatal women, the current study revealed that slightly more than four fifth of women age ranged from 20-30 years, with mean age 25.19 years \pm 4.18. This finding is in line with Hassan H., ELKholy G., Ateya A., and Hassan A (2020) ${ }^{(16)}$ who implied that the women age ranged from 20-30 years with a mean age 23.25 years $\pm \mathbf{5 . 7 5}$ in their study of breastfeeding knowledge and practices among primiparous women with caesarean section: impact on breast engorgement in upper Egypt. From the researcher point of view these similarity may be due to that it is the normal age of childbirth.

Regarding women residence, the present study declared that slightly less than three fifth of women were from rural areas. This result was in agreement with Abdallah N., Eldin S., and Gad A (2018) (17) who studied breast and nipple problems encountered among puerperal primipara women in Zagazig, they mentioned that the majority of the studied women were from rural areas. The present study is on contrast with Jhade J., and Shiju D (2019) (18) who assessed the effectiveness of the structured teaching program on knowledge regarding prevention and management of post-natal breast complications among primigravida mothers. They demonstrated that nearly three quarters of the studied women were from urban areas and the rest 
of them were from rural areas. This discrepancy may be related to different setting where the study was conducted.

In relation to women's age at marriage and duration of current marriage, the present study revealed that the mean age at marriage was 22.94 years $\pm \mathbf{4 . 0 8}$ and the mean duration of current marriage was 1.94 years \pm 1.09. These results are contradicted with Hassan H., EL-Kholy G., Ateya A., and Hassan A (2020) (16) who clarified that the studied women mean age at marriage was $21.62 \pm \mathbf{6 . 2 5}$ years and the duration of current marriage was $\mathbf{4 . 0 5}$ \pm 3.05. This difference may stem from Hassan H., EL-Kholy G., Ateya A., and Hassan A (2020) ${ }^{(16)}$ study conducted in Upper Egypt where the phenomenon of early marriage is widespread.

According to the women's educational level, the findings of the present study revealed that nearly two fifth of them had secondary school. These findings are in line with Pardeshi P., Pathak N., Patil A., Shaikh T., Raut S., and Bera L (2019) (19), who mentioned that the majority of the studied women had secondary education.

In contrast with Varghese B., and Patwa A (2020) ${ }^{(20)}$ who assess the effectiveness of hospital based teaching program on knowledge regarding home management for breast engorgement among postnatal mothers. They reported that the majority of the studied women had primary education. This difference may be due to different study settings. As regards to the women's occupation, the findings of the present study revealed that the vast majority of women were housewife. This result is in agreement with Prasad Y., Chandrakala P., and Manasa G (2017) ${ }^{(21)}$, who stated that the higher percent of the studied women were house wives. On the other hand, these findings are inconsistent with Abd El-Salam A., and Ashour E (2020) ${ }^{(22)}$ who illustrated that most of the studied women were working. This may be due to the majority of the studied women have a low level of education and from rural areas, which leads to decrease their work opportunities.

Concerning the type of family; the current study revealed that nearly three fifth of women were from nuclear family. This study is in match with Aneesha V., Baby M., Neena K., Sunny R., and Souparnika P (2019) ${ }^{\text {(23) }}$ who mentioned that half of studied women belong to nuclear family. On the other hand, the result is contradicted with Hassan H., ELKholy G., Ateya A., and Hassan A (2020) ${ }^{(16)}$ who reported that more than half of studied women were from extended families. From the researcher point of 
view; this may be justified by diversity in customs and beliefs between the studies settings, as people in Upper Egypt prefer to live in extended family to be supported by each other, while in Lower Egypt they prefer living in nuclear family to avoid the family conflicts.

Regarding the number of family members; the present study showed that nearly three fifth of women had three family members. It is contradicted with Hassan H., ELKholy G., Ateya A., and Hassan A (2020) ${ }^{(16)}$ who reported that more than half of the women had more than five family members. From the researcher point of view this discrepancy may be related to that the studied women belong to extended family. Concerning the family income; the present study revealed that more than four fifth of women had enough income. This finding is in line with Ebrahim R., and Esmat O (2018) ${ }^{(24)}$ who reported that the higher percent of studied women had enough income which covers family needs. On the other hand, this finding is inconsistent with Hassan H., EL-Kholy G., Ateya A., and Hassan A (2020) (16) who mention that most of the studied women haven't enough income. This may be explained from the researcher point of view due to different of socioeconomic circumstance among the studied groups.
Concerning women's reproductive history, the result of the present study clarified that the majority of women were primigravida, such result agrees with Salgaonkar R (2019) (25) who assessed the effect of chilled cabbage leaves application on breast engorgement among post-natal mothers admitted in selected hospital of Navi Mumbai. He reported that the majority of studied sample were gravida one. As regards to the gestational age, the finding of the present study demonstrated that the mean of gestational age was 39.32 weeks \pm 1.30 . This finding is in accordance with Alekseev N et al., (2015) (27) who studied pathological postpartum breast engorgement: prediction, prevention, and resolution. They indicated that the mean gestational age was 39 weeks $\pm \mathbf{1 . 4}$.

In relation to attendance of antenatal care, majority of the women attended antenatal care regularly, sought initial antenatal visit at first trimester and had more than four antenatal visits through the pregnancy course. The present study findings is in harmony with Hassan S., NourEldin S., and Abd-Allah I (2019) ${ }^{(28)}$ who stated that the majority of the studied women received antenatal care during the first trimester and had more than four visits through the pregnancy course. On the other hand, this finding is inconsistent with 
Hassan H., EL-Kholy G., Ateya A., and

Hassan A (2020) ${ }^{(16)}$ who mentioned that nearly two third of women didn't receive antenatal care. This may be due to lack of health center services that provide antenatal care for pregnant women in Upper Egypt.

Regarding the place of antenatal care, the majority of women had antenatal care at the private clinics or hospitals. This finding is contradicted with Varghese B., and Patwa A (2020) ${ }^{(20)}$ who mentioned that most women went to governmental hospitals for antenatal care. From the researcher point of view the result in the present study may be due to the antenatal care and facilities which provided to pregnant women at private clinics and hospitals are better than care provided at the governmental hospitals.

Concerning the attendance of antenatal care classes; the present study revealed that the minority of the women attended antenatal care classes and more than three fifth of them received classes by doctor one to two times at the health and $\mathrm{MCH}$ centers. This finding is supported by Prasad Y., Chandrakala P., and Manasa G (2017) (21) who showed a great deficiency in the health education received during antenatal visits. On the other hand, this finding is inconsistent with Abdallah
N., Eldin S., and Gad A (2018) ${ }^{(17)}$, who reported that the main source of women's antenatal health education was from families and friends. This may be due to that the majority of the studied women in the present study had antenatal care at private clinics or hospitals.

In relation to topics of health education classes, the present study revealed that the majority of women who received antenatal classes mentioned that breastfeeding education is the most common topic received. This finding is contradicted with Karatay G., Gurarslan N., and Orhan Ergin I (2018) ${ }^{(29)}$ who mentioned that most women didn't receive health education regarding breastfeeding during their antenatal visits. This result is accepted because the majority of the studied women were housewives, living in rural area, and lacking awareness about breastfeeding problems and their management. This may also reflect the deficiencies at health institutions regarding their roles in health education as the health care providers focus mainly on serious cases and neglect health teaching about such topics for pregnant women, especially primiparae. So, this may lead to various breast problems which interfere with the establishment and continuation of breastfeeding. 
As regards to the mode of delivery, more than three quarters of women had cesarean section with spinal anesthesia, 1.37 hours $\mathbf{\pm 0 . 5 3}$ mean length of labor and nearly one quarter of women had normal vaginal delivery with episiotomy, $\mathbf{1 3 . 3 7}$ hours $\mathbf{\pm 5 . 8 9}$ mean length of labor. These results are similar with Karatay G., Gurarslan N., and Orhan Ergin I (2018) ${ }^{(29)}$, who reported that nearly three quarter of women had cesarean section. On the other hand, the present study contradicted with El-Saidy T., and Aboushady R (2016) ${ }^{(30)}$ who reported that nearly three quarter of women had normal vaginal delivery and the rest of them had cesarean section. In relation to the number of postpartum days, the present study findings clarified that the mean number of postpartum days was $\mathbf{5 . 8 4}$ \pm 8.57. This finding contrasts with ElSaidy T., and Aboushady R (2016) (30) who reported that mean number of postpartum days was $\mathbf{3 . 8} \pm \mathbf{0 . 7}$. This difference may be due to that the researcher in the present study selected the studied women within the first 40 days after delivery according to the study inclusion criteria.

Regarding the breastfeeding initiating time, the finding of the present study revealed that minority of the studied women initiated breastfeeding immediately after delivery and nearly half of them initiated within two hours. This finding is in the same line with Shrooti S., Prativa D., and Devkumari S (2016) ${ }^{(31)}$ who mentioned that half of studied women initiated breastfeeding within 2 hours after delivery. On the other hand, the finding disagrees with Ebrahim R., and Esmat O (2018) ${ }^{(24)}$ who reported that more than of women initiated breastfeeding after more than two hours. From the researcher point of view, this difference may be due to lack of anticipatory guidance and support to initiate breastfeeding immediately after delivery, in addition to the pain resulted from caesarian section and episiotomy among the studied women who had vaginal delivery. This is may be attributed to delay in establishing breastfeeding.

Regarding the duration of breastfeeding, the vast majority of women reported that the duration of breastfeeding was 10 minutes. This finding matched with Abdallah N., Eldin S., and Gad A (2018) (17) who reported that most of studied women fed their infants for less than 15 minutes. On the other hand, the present study contradicted with Hassan H., ELKholy G., Ateya A., and Hassan A (2020) ${ }^{(16)}$ who reported that more than half of women fed their babies for less than 10 minutes. From the researcher point of 
view, these results may be due to lack of primpara women's experience and knowledge regarding breastfeeding technique.

As regard to the frequency of breastfeeding, slightly more than four fifth of women fed their infants on demand. This finding is in contrast with Ebrahim R., and Esmat O (2018) ${ }^{(24)}$ who reported that more than two thirds of the studied women fed their infants four times per /day. The result of the present study was accepted because the World Health Organization and the United Nations Children's Emergency Fund recommended that breastfeeding should be on-demand not on any strict schedule ${ }^{(32)}$.

The result also showed that the entire study women used sitting position during breastfeeding. This result contrasts with Angeline A., Yesudas M., and John N (2020) ${ }^{(33)}$ who reported that nearly three quarters of the studied women used sitting position and the rest of them used side lying position. Regarding feeding the infant from both breasts, the finding of the present study revealed that the vast majority of women fed their infants from both breasts. This is in line with Hassan S., and Abdelwahed W (2015) ${ }^{(34)}$ who mentioned that most of the participants used both breasts to feed their infants.
As regard to total score level of knowledge regarding breast engorgement. It is noticed that more than three quarters of women exhibited poor level of knowledge regarding breast engorgement. This study finding is similar to Sunita K., and Deepika R (2020) ${ }^{(35)}$ and Hemavathy V., Sarathi S., and Shekharan G (2019) ${ }^{(36)}$, who reported that there was low level of women's knowledge regarding breast engorgement. On the other hand, the results were contradicted with Aneesha V., Baby M., Neena K., Sunny R., and Souparnika P (2019) ${ }^{(23)}$ who reported that the majority of women had good knowledge. This discrepancy with the current study may be related to different educational level among the studied women.

Regarding the source of knowledge, the current study revealed that nearly half of women mentioned that family were a primary source of knowledge regarding breast engorgement, while the minority of them receives their knowledge from books and magazines. This study finding is supported by Abd El-Salam A., and Ashour E (2020) ${ }^{(22)}$ who demonstrated that family members were the most common source of women's knowledge. While Hassan H., EL-Kholy G., Ateya 
A., and Hassan A (2020) ${ }^{(16)}$, declared that midwifes were the most common sources of women's knowledge. From the researcher point of view; this may be attributed to that the majority of the studied women were primipara who were dependent on their families to gain knowledge and this is serious, because such knowledge may be inadequate, inaccurate and incomplete.

The study also shows that only less than one fifth of women actually suffered from breast engorgement during postnatal period. This result matched with Angeline A., Yesudas M., and John N (2020) ${ }^{(33)}$, who clarified that less than one fifth had breast engorgement as abreast complication occur among postnatal women. On the other hand, this finding is inconsistent with Karatay G., Gurarslan N., and Orhan Ergin I (2018) ${ }^{(29)}$ who stated that three fifth of postnatal women had breast engorgement during postnatal period.

In relation to women's self-care practices that were performed to relief breast engorgement; all women expressed their breast manually before putting the infant on breast and the vast majority of them increased frequency of breastfeeding, used breast pump, nursed their infants on demand, used correct latch and positioning of infant during breastfeeding and fed the infants at least 15 to 20 minutes at each breast or until breast become soft. This result is matching with Pustotina $O$ (2016) ${ }^{(12)}$ who founded that the pumping of breast milk is effective method to prevent breastfeeding problems. Also Myles K., Weiss J., Dunn S., Peterson W., and Cotterman K (2015) ${ }^{(37)}$ reported that use of breast pumps reduced the postpartum breast engorgement. On the other hand, the study finding is not matching with the finding of Karatay G., Gurarslan N., and Orhan Ergin I (2018) ${ }^{(29)}$, who stated that only one fifth of the studied women expressed their breast manually or used breast pump.

Furthermore, less than one quarter of women used moist heat on breasts for few minutes before breastfeeding, made gentle massage and compressed the breast when the infant pauses between sucking. This result is supported by Witt A., Bolman M., Kredit S., and Vanic A (2016) (38) who found that the therapeutic breast message during the lactation period was useful in reducing breast engorgement.

Regarding the total score level of LATCH Breastfeeding Charting Scale; the present study showed that nearly two thirds of women had fair level of breastfeeding. This finding is similar to Abbas I., and 
Hasan R (2015) (39) who assess the LATCH score regarding breastfeeding among women after child birth. They reported that the highest percentages of the study sample had fair score of LATCH breastfeeding assessment. This may stem from the enrolled postnatal women in this study were primipara with lack of experience.

As regard to relationship between studied primipara post-natal women's sociodemographic data and their total knowledge scores about breast engorgement, the current study reported statistical significant relation between women's occupation, family income and their total knowledge scores. These results are similar to the finding of the study done by Pardeshi P., Pathak N., Patil A., Shaikh T., Raut S., and Bera L (2019) (19), who stated that there was a statistical significant relation between women's total knowledge and occupation. On the other hand, the current study finding is contradicted with Aneesha V., Baby M., Neena K., Sunny R., and Souparnika $P$ (2019) ${ }^{(23)}$, who mentioned that there was no significant associations between occupation and women's total knowledge scores.

Concerning the relationship between sociodemographic data and total self-care practice score of the studied women, the current study revealed that there was a statistical significant relationship between total self-practice scores and both women's educational level and occupation. These results were matched with Aalrazek A (2013) (40) who mentioned there was a significant association between performance score regarding self-care during postnatal period and the educational level of the studied women.

Moreover, the current study revealed presence of significant relationships between total Latch Breastfeeding Charting Scale scores and the following; women's age, educational level, occupation, type of family and number of family members. This result is in the same line with Abbas I., and Hasan R (2015) (39), who reported that there was a statistical significant relationship between age of women and LATCH Breastfeeding Charting Scale. In the same time, it is in contrast with Abbas I., and Hasan R (2015) ${ }^{(39)}$, who reported that there was no statistical significant relationship between educational level and LATCH Breastfeeding Charting Scale. From the researcher point of view, educational level plays an important role which influences the women's ability for effective and exclusive breastfeeding. Women with a 
higher education level tend to initiate breastfeeding more often, and also tend to breastfeed their child for a longer period of time and more effectively than women with low education. Maternal employment is also an important factor as women who work have better chances to gain valuable health and social information.

\section{Conclusion}

Based on the findings of the present study, it can be concluded that primpara postnatal women had a poor level of knowledge as well as unsatisfactory level of self -care practices regarding breast engorgement. Furthermore, this study also revealed that the total level of LATCH Breastfeeding Charting Scale was significantly fair among nearly two thirds of the studied women.

\section{Recommendations}

Based on the findings of the present study, the following recommendations are derived and suggested

- Planning and developing antenatal classes for all women to increase their knowledge and enhance their self-care practices regarding breast engorgement.

- Additionally, supportive care should be available to lactating primipara women within the first 24 hours after birth and throughout the early postpartum period.

\section{References}

1. Kansky C. Normal and abnormal puerperium: Overview, routine postpartum care, hemorrhage. Available from: https://emedicine.medscape.com/articl e/260187-overview. Retrieved at 2016.

2. Lim A., Song J., Hur M., Lee MK., andLee M. Cabbage compression early breast care on breast engorgement in primiparous women after cesarean birth: A Controlled clinical trial. International Journal of Clinical and Experimental Medicine, 2015; 11(8): 21335-342.

3. Salvo S. Massage Therapy E-Book: Principles and Practice. $6^{\text {th }}$ ed., United States of America, Elseveir Com., 2020; 618.

4. Suresh S., Sharma K., Saksena M., Thukral A., Agarwal R., and Vatsa M. Predictors of breast feeding problems in the first postnatal week and its effect on exclusive breastfeeding rate at six months. Indian Journal of Public Health, 2014; 58(4): 270-3.

\section{Lawrence RA., andLawrence RM.} Breastfeeding: A Guide for the Medical Profession. $8^{\text {th }}$ ed., United States of America, Elseveir Com., 2016; 250-2. 
6. Indrani D., and Sowmya M. A Study to find the prevalence of breast engorgement among lactating mothers. Journal of Reproductive Medicine Gynaecology and Obstetrics, 2019; 4(23):1-5.

7. Priyanka P., Basavaraj C., Ramannavar A., Kurhade G., Kurhade A., Vaillant A., Powar R., and Vuma S. Comparative effect of ultrasound therapy with conventional therapy on breast engorgement in immediate postpartum mothers: A Randomized controlled trial. Integrative Molecular Medicine Journal, 2016; 3(2): 553-8.

8. Disha RA., Singh A., and Suri V. Effect of chilled cabbage leaves vs. hot compression on breast engorgement among post-natal mothers admitted in a tertiary care hospital. Nursing and Midwifery Research Journal, 2015; 11(1): 24-32.

9. Hassan H., Gamel W., Hassanine SH., and Sheha E. Fenugreek seed poultice versus cold cabbage leaves compresses for relieving breast engorgement: An interventional comparative study. Journal of Nursing Education and Practice, 2020; 10(5): 82-99.
10. Nanthini R., and Bhuvaneswari G. A Study to assess the effectiveness of cold cabbage leaves vs hot water application on breast engorgement among postnatal mothers in selected hospital, Chennai. International Journal of Science and Research, 2015; 4 (9): 838-42.

11. John L., Cordeiro M., Manjima M., Gopinath R., and Tamrakar A. Knowledge regarding breast problems among antenatal mothers in a selected hospital. International Journal of Recent Scientific Research, 2015; 6(9): 6228-31.

\section{Jensen D., Wallace S., and Kelsay $P$.} LATCH: A Breastfeeding Charting System and Documentation Tool. Journal of Obstetric, Gynecologic, and Neonatal Nursing, 1994; 23(1): 27-32.

13. Dawson BD., and Trapp RG. Reading the Medical Literature: Basic and Clinical Biostatistics. Lange Medical Book/ Mcgraw - Hill. $3^{\text {rd }}$ ed., New York, Medical Publication Division Com., 2001; 161-218, 30514.

\section{Department of Health and Human}

Services. The business case for breastfeeding. Retrieved from: https://ucsd communityhealth.org/wpcontent/uploads/2016/04/6.Supporting 
-Breastfeeding-Employees-Business-

Case.pdf. Available at: 2016.

15. Mahiba J. Prevention and management of breast engorgement among primi postnatal mothers effectiveness of structured teaching programme. Manager's Journal on Nursing, 2018; 2(1): 29-33.

16. Hassan H., EL-Kholy G., Ateya A., and Hassan A. Breastfeeding knowledge and practices among primiparous women with caesarean section: Impact on breast engorgement in Upper Egypt. Communication, Society and Media Journal, 2020; 3(2): 34-69.

17. Abdallah N., Eldin S., and Gad A. Breast and nipple problems encountered among puerperal primipara women in Zagazig. International Journal of Pharmaceutical Research and Allied Sciences, 2018; 7(1): 183-195.

18. Jhade J., and Shiju D. A Study to assess the effectiveness of the structured teaching programme on knowledge regarding prevention and management of postnatal breast complications among primigravida mothers. International Journal of Nursing and Health Research, 2020; 2(1): 11-16.
19. Pardeshi P., Pathak N., Patil A., Shaikh T., Raut S., and Bera L. Assess knowledge regarding breast complication during puerperium among postnatal mothers. The Pharma Innovation Journal, 2019; 8(6): 133-135.

20. Varghese B., and Patwa A. Effectiveness of hospital based teaching programme on knowledge regarding home management for breast engorgement among postnatal mothers. International Journal of Research and Review, 2020; 7(6): 2454-237.

21. Prasad Y., Chandrakala P., and Manasa G. Common breast feeding problems in mothers in early postnatal period. International Journal of Contemporary Pediatrics, 2017; 6(2): 625-8.

22. Abd El-Salam A., and Ashour E. Effectiveness of video assisted teaching program on postpartum minor discomforts of primipara mothers. American Journal of Nursing Research, 2020; 8(2): 142-50.

23. Aneesha V., Baby M., Neena K ., Sunny R., and Souparnika $P$. Knowledge regarding breast engorgement among primi postnatal mothers admitted in Amala Institute 
Medical Sciences, Thrissur. Journal of Midwifery, Women Health and Gynaecological Nursing, 2019; 2(1): 26-33.

24. Ebrahim R., and Esmat O. Effect of educational program on mothers' using for non-pharmacological therapies to alleviate breast engorgement after cesarean section. International Journal of Novel Research in Healthcare and Nursing, 2018, 5(2): 454-69.

25. Salgaonkar R. A Study to assess the effect of chilled cabbage leaves application on breast engorgement among post-natal mothers admitted in selected hospital of Navi mumbai. International Journal of Nursing Research, 2019; 5 (1): 1-4.

\section{Chaudhary P., Banu T., and Farswal}

A. A Study to assess the effectiveness of olive oil massage in reducing breast engorgement and pain among postnatal mothers with LSCS Admitted in selected hospital at Meerut. International Journal of Nursing and Midwifery Research, 2019; 6(4): 14-21.

27. Alekseev N., Vladimir L., and Nadezhda T. Pathological postpartum breast engorgement: Prediction, prevention, and resolution.
Breastfeeding Medicine Journal, 2015; 10(4): 203-8.

28. Hassan S., NourEldin S., and AbdAllah I. Effect of prenatal educational programme on women's knowledge for prevention of breastfeeding problems after cesarean delivery. Journal of Nursing and Health Science, 2019; 1(2): 43-50.

29. Karatay G., Gurarslan N., and Orhan Ergin I. Traditional practices of Turkish mothers at breast engorgement during postpartum period. International Journal of Caring Sciences, 2018; 11(3): 1954-62.

30. El-Saidy T., and Aboushady $R$. Effect of two different nursing care approaches on reduction of breast engorgement among postnatal women. Journal of Nursing Education and Practice, 2016; 6(9):18-25.

\section{Shrooti S., Prativa D., and} Devkumari S. Knowledge and practice related to breastfeeding among caesarean section mothers of BPKIHS, Dharan, Nepal. International Journal of Health Sciences and Research, 2016; 6(3): 213-7.

32. Nyqvist K., Maastrup R., Hansen M., Haggkvist A., Hannula L., Ezeonodo A., Kylberg E., Frandsen A., and 
Haiek L. Neo-BFHI: The babyfriendly hospital initiative for neonatal wards. Nordic and Quebec Working Group, 2015; 5(2): 15-45.

\section{Angeline A., Yesudas M., and John}

N. A Study to assess the effectiveness of planned teaching programme on knowledge and practice regarding the breast problems and its management among postnatal mother in selected hospitals, KOLLAM. International Journal of Scientific Research, 2020; 9 (1): 8-11.

34. Hassan S., and Abdelwahed W. Knowledge andpractices of exclusive breastfeeding in Fayoum, Egypt. Public Health and Community Medicine Department Fayoum University. The Egyptian Journal of Community Medicine, 2015; 33(1): 61-77.

35. Sunita K., and Deepika R. Effectiveness of structured teaching programme on knowledge regarding prevention of breast engorgement among postnatal mothers in Haryana. International Journal of Creative Research Thoughts, 2020; 8(4): 2320-882.

36. Hemavathy V., Sarathi S., and Shekharan G. A Study to assess the effectiveness of lactational counselling on breast engorgement among postnatal mothers at selected hospital in Chennai. International Journal of Current Advanced Research, 2019; 8(05): 18897-9.

37. Myles K., Weiss J., Dunn S., Peterson W., and Cotterman $K$. Maternal intravenous fluids and postpartum breast changes: A Pilot observational study. International Breastfeeding Journal, 2015; 10(18): 2-9.

38. Witt A., Bolman M., Kredit S., and Vanic A. Therapeutic breast massage in lactation for the management of engorgement, plugged ducts, and mastitis. Journal of Human Lactation, 2016; 32(1): 123-31.

39. Abbas I., and Hasan R. Assessment of LATCH Tool regarding initiation of breastfeeding among women after childbirth. Journal of Engineering, 2015; 5(5): 38-44.

40. Aalrazek A. Enhancement of mother's self-care practices for relieving minor discomfort during postpartum period. Asian Academic Research Journal of Social Sciences and Humanities, 2013; 1(13): 316-31. 